\title{
TEKNIK PEMANENAN MADU LEBAH HUTAN OLEH MASYARAKAT SEKITAR HUTAN DI KECAMATAN MALLAWA KABUPATEN MAROS
}

\author{
Technique of Forest Honeybee Harvesting Praticed by Local Community around the Forest Area in \\ District of Mallawa, Regency of Maros
}

\section{A. Mujetahid M.}

\begin{abstract}
This research purpose to understand the technique of forest honey bee harvesting and income of local community who harvest the honey of forest honey bee in District of Mallawa, Regency of Maros. Data was obtained through observation, intervieuw and discussion method to the related stakeholders and collected by using purpossive sampling method. The number of respondents involved in this research were 30 persons. Data that have been collected then calculated, tabulated and descriptively analyzed according to research objective. The result of research shows that technique of forest honeybee harvesting consists of several steps. The first step was preparation of harvesting tools such as amung used for smoking the honey comb, kondre for putting the honey comb in container and stain for climbing the tree. The next steps were climbing the tree, taking and sorting the honey comb from the tree, putting down the honey comb, compressing the honey comb and packing the honey. Harvest yield of honey was 1,601,25 kg/year or Rp $28,200,000 /$ year or the average was Rp. $940,000 /$ year.
\end{abstract}

Key words: Technique harvesting, honey bee, local community around the forest area, income

\section{PENDAHULUAN}

Madu digunakan sebagai pemanis sejak zaman prasejarah sebelum adanya gula. Madu tersebut diproduksi oleh lebah, baik oleh lebah liar maupun budidaya. Sampai saat ini pun madu masih banyak dikonsumsi oleh masyarakat di Indonesia dan dapat diperoleh dengan mudah di berbagai tempat. Kecamatan Mallawa adalah salah satu kecamatan di Kabupaten Maros yang sebagian besar penduduknya melakukan aktivitas pemanenan madu lebah hutan dalam jumlah yang cukup besar. Informasi tentang teknik yang dilakukan dalam kegiatan pemanenan madu dan besarnya produksi hasil hutan bukan kayu ini belum didokumentasikan sehingga informasi tersebut masih terbatas. Sehubungan dengan itu maka dianggap penting untuk melakukan penelitian tentang teknik pemanenan madu lebah hutan yang dilakukan oleh masyarakat di daerah tersebut.

Bertitik tolak dari latar belakang yang diuraikan di atas, maka tujuan yang ingin dicapai dalam penelitian ini adalah untuk mengetahui teknik pemanenan madu lebah hutan yang dilakukan oleh masyarakat dan tingkat pendapatan masyarakat hasil panen madu di Kecamatan
Mallawa Kabupaten Maros. Hasil penelitian ini diharapkan dapat berguna sebagai bahan informasi mengenai teknik pemanenan dan pendapatan hasil panen madu lebah hutan.

\section{BAHAN DAN METODE}

Penelitian ini dilaksanakan di Kecamatan Mallawa, Kabupaten Maros pada bulan April sampai November 2005. Pengumpulan data dilakukan dengan teknik observasi/survei, wawancara dan diskusi dengan stakeholder yang ada kaitannya dengan penelitian ini (purposive sampling). Jumlah responden sebanyak 30 orang dengan kriteria masyarakat tersebut mempunyai pekerjaan pokok atau sampingan sebagai pemanen madu lebah hutan. Disamping itu terdapat informan yang diwawancarai seperti aparat dan tokoh masyarakat desa. Data yang telah dikumpulkan diolah, ditabulasi dan diklasifikasikan sesuai dengan tujuan penelitian dan selanjutnya dianalisis secara deskriptif. Sedangkan jumlah produksi madu dihitung dengan menggunakan formula sebagai berikut: 
Jumlah produksi madu $=$ A $/ B$

di mana:

$\mathrm{A}=$ Jumlah madu yang dipanen $(\mathrm{kg})$

$B=$ Musim panen (tahun)

\section{HASIL DAN PEMBAHASAN}

\section{Teknik Pemanenan Madu Lebah Hutan}

Masyarakat Kecamatan Mallawa pada umumnya bermata pencaharian sebagai petani dengan jenis tanaman jangka pendek seperti padi, kacang-kacangan, jagung, lombok, tomat, tembakau, dan tanaman jangka panjang seperti coklat dan kemiri. Selain bertani masyarakat juga menjadikan pencarian madu lebah hutan sebagai mata pencaharian sampingan. Walaupun pencarian madu ini merupakan pekerjaan sampingan, tetapi mendapat perhatian yang lebih besar daripada pekerjaan sampingan lainnya, karena dapat membantu dalam memenuhi perekonomian keluarga terutama kebutuhan sehari-hari.

\section{Jenis pohon inang dan proses pencarian sarang}

Pada pertengahan musim kemarau, pemanen madu mulai mencari sarang lebah. Lebah ini biasanya bersarang pada pohon dengan daun yang lebat. Pohon tempat lebah bersarang disebut dengan pohon inang. Pohon inang tersebut antara lain beringin (Ficus sp), mangga (Mangifera indica), kemiri (Aleurites mollucana), Polanceng, dan Ajumerana seperti dapat dilihat pada Tabel 1.

Dalam melakukan pencarian sarang, para pemanen membawa peralatan sederhana seperti parang yang akan digunakan untuk menandai pohon inang, terutama pohon inang yang mempunyai sarang lebah yang belum siap panen agar tidak diambil oleh pemanen lain. Penandaan ini antara lain dengan menuliskan atau memahatkan inisial nama pada batang pohon, memberi tanda silang $(\mathrm{x})$, atau mengikatkan batang liana (rotan, lamollo, salampe) pada pohon inang. Pencarian sarang biasanya bersamaan dengan proses pemanenan madu, tergantung kematangan sarang. Adapun ciri sarang siap panen antara lain ukuran sarang memendek atau mengecil, bagian bawah sarang menipis dan keadaan sekitar sarang terlihat bersih. Disamping itu, pemanen juga memperhatikan jumlah koloni dalam setiap pohon inang. Rata-rata jumlah koloni dalam satu pohon inang adalah satu, akan tetapi tidak jarang para pemanen menemukan 2-3 koloni.

\section{Persiapan pemanenan madu lebah hutan}

Pemanenan madu di Desa Bentenge dilakukan pada akhir musim kemarau hingga awal musim penghujan, karena pada musim kemarau lebah-lebah pekerja mengumpulkan nektar dari bunga yang ada di sekitar sarang. Pada umumnya bulan-bulan panen ini berkisar antara September sampai dengan Desember setiap tahunnya. Berdasarkan hasil wawancara dan pengamatan lapangan, diketahui bahwa tidak ada perbedaan cara memanen madu lebah hutan dari setiap pemanen. Untuk melakukan pemanenan memerlukan peralatan seperti parang, jerigen, plastik, kondre (keranjang anyaman rotan), tangga dan amung (alat pengasap sarang). Untuk lebih jelasnya dapat dilihat pada Tabel 2.

Pemanen madu melakukan pemanenan secara berkelompok yaitu 2-4 orang, dengan pembagian kerja sesuai dengan keterampilan yang dimiliki. Pada umumnya ketua kelompok berperan sebagai pemanjat dan mengarahkan anggota lainnya dalam melakukan persiapan. Persiapan dilakukan sejak dalam perjalanan mencari atau menuju sarang lebah dengan mengumpulkan batang liana seperti rotan, lamollo dan salampe (bahasa lokal). Setelah menemukan sarang yang siap panen, maka setiap anggota melaksanakan tugasnya masing-masing, seperti membuat kondre, memasang tangga, membuat amung, dan pemanjat.

Table 1. Host tree species of forest honeybee at Mallawa District, Maros Regency

\begin{tabular}{|c|c|c|c|}
\hline \multirow{2}{*}{ No } & \multicolumn{2}{|c|}{ Nama } & \multirow{2}{*}{ Masa Berbunga } \\
\hline & Lokal & Latin & \\
\hline 1. & Beringin & Ficus sp & September - November \\
\hline 2. & Kemiri & Aleurites mollucana & Oktober - November \\
\hline 3. & Mangga & Mangifera indica & Oktober - November \\
\hline 4. & Polanceng & *) & September - November \\
\hline 5. & Ajumerana & $*$ & September - Oktober \\
\hline
\end{tabular}

Remarks: *) unidentified 
Table 2. Harvesting tools of forest honeybee used by local community at Bentenge Village, Mallawa District, Maros Regency

\begin{tabular}{cll}
\hline No. & Nama Alat & \multicolumn{1}{c}{ Kegunaan } \\
\hline 1. & Parang & Untuk memotong batang liana atau pohon yang tumbang \\
2. & Jerigen plastik & Wadah madu, jika sarang diperas di dalam hutan \\
3. & Plastik & Wadah tempat madu diturunkan \\
4. & Kondre & Wadah untuk menurunkan sarang lebah \\
5. & Amung & Alat pengasap sarang lebah \\
6. & Topi, Baju dan celana & Untuk mengamankan tubuh pemanjat dari sengatan labah \\
7. & Tanjang, sarung pada leher & Untuk memudahkan sampai di sarang \\
\hline
\end{tabular}

\section{a. Pembuatan kondre}

Kondre merupakan keranjang yang terbuat dari anyaman rotan yang digunakan sebagai wadah untuk menurunkan sarang dari pohon inang. Rangka kondre ini berbentuk seperti ember dengan tinggi $30-100 \mathrm{~cm}$ dan berdiameter antara $40-100 \mathrm{~cm}$ dan atau disesuaikan dengan ukuran sarang. Anyaman rotan pada kondre ini dililit oleh batang liana, agar simpul yang ada menjadi lebih rapat Setelah rangka terbentuk, kondre ini dialasi dengan daun katimpang muda yang digunakan sebagai pengalas. Kondre ini diikat kembali dengan batang liana sampai sarang diturunkan.

\section{b. Pembuatan amung}

Teknik pemanenan madu ini dilakukan secara tradisional yakni dengan cara memanjat pohon dan menggunakan pengasapan. Amung adalah alat pengasap yang terbuat dari kayukayu kering yang digunakan untuk mengusir lebah. Ranting-ranting kering yang dikumpulkan dalam perjalanan menuju sarang maupun di daerah sekitar sarang, diikat dan dikumpulkan menjadi satu dengan diameter $\pm 10 \mathrm{~cm}$. Amung dibungkus dengan daun katimpang muda sampai ranting-ranting kering ini tidak kelihatan lagi, kemudian dengan batang liana dibuat pengait untuk memudahkan pada saat pemanjatan untuk pengasapan.

Jumlah amung yang digunakan pada setiap pengasapan berbeda-beda, tergantung arah tiupan angin. Jika angin bertiup tidak terlalu kencang dapat menghabiskan satu amung, akan tetapi jika angin bertiup kencang dan ke segala arah menghabiskan $1-2$ amung.

\section{c. Pembuatan tangga}

Tangga berfungsi untuk membantu pemanjat dalam mengambil sarang lebah di atas pohon inang. Tangga yang digunakan adalah batang pohon yang telah tumbang, kemudian dirapatkan dan diikat dengan salampe pada pohon inang sehingga ikatan ini dijadikan pijakan oleh si pemanjat.

Pembuatan dan pemasangan tangga dilakukan pada setiap pohon inang karena jarak yang cukup jauh, disamping bahan yang mudah diperoleh. Resiko pemanjatan dalam pemanenan madu lebah hutan ini adalah terjatuh dari pohon inang akibat ikatan tangga yang kurang kuat, batang kayu yang lemah atau kesalahan lain pada saat pembuatan tangga.

\section{Teknik pemanenan madu lebah hutan}

Proses pemanenan madu lebah hutan di Desa Bentenge ini diawali dengan pengusiran lebah melalui pengasapan, pemanjatan pohon inang, penyortiran sarang lebah, dan penurunan sarang dengan menggunakan keranjang rotan atau kondre. Tahapan ini dilakukan setelah alat-alat yang dibuat pada tahap persiapan telah selesai dan siap untuk digunakan.

Pertama-tama pemanen membasahi amung dengan air pada bagian atas agar api tidak cepat merambat dan asap yang dihasilkan banyak, kemudian pada bagian bawahnya dibakar dengan bantuan minyak tanah atau sepotong sendal jepit bekas sebagai pancingan api. Amung yang sudah mulai terbakar dikaitkan pada sebatang kayu yang panjangnya \pm 5 meter untuk memudahkan proses pengasapan yang dapat mencapai tepat di bawah sarang. Pada saat pengasapan, lebah mulai 
keluar dari sarang dan pemanjatan pohon inang dimulai dengan tetap membawa amung sampai lebah meninggalkan sarang. Pemanjatan ini dilakukan dengan menggunakan tangga yang telah disiapkan pada tahap persiapan, sedangkan pemanjat hanya menggunakan topi sebagai pelindung kepala, baju dan celana panjang sebagai pelindung tubuh, serta sarung yang diikatkan pada kepala dan leher pemanjat. Tinggi sarang tempat koloni bergantung sangat beragam mulai dari 5 - 30 meter.

Penyortiran sarang dimulai dengan memotong sarang secara vertikal dan mengeluarkannya dari cabang pohon. Sarang yang masih tersisa pada cabang pohon dimasukkan terlebih dahulu ke dalam kondre dan disusul dengan potongan-potongan sarang sebelumnya. Kondre diturunkan dengan cara diselempangkan pada tubuh pemanjat atau menggunakan tali dengan cara mengulur. Pengeluaran madu dari sarang dan pengemasannya dilakukan oleh istri-istri pemanen setelah tiba di rumah. Madu ini dikemas dengan menggunakan botol kecap atau bir. Sedangkan pembagian hasil panen madu lebah hutan tergantung kesepakatan kelompok, ada yang berbentuk madu yang dihitung berdasarkan jumlah botol dan pembagian dalam bentuk uang yang dilakukan setelah madu laku terjual.

\section{Produksi Madu}

Jumlah hasil pemanenan madu lebah hutan sebanyak 1.880 botol $(1.601,25 \mathrm{~kg})$ per tahun dengan rata-rata 62,66 botol $(53,27 \mathrm{~kg})$ setiap pemanen per tahunnya. Kemasan madu menggunakan botol kecap atau botol bir dengan harga Rp 15.000,- per botolnya. Pendapatan masyarakat pemanen madu ini sebesar Rp 28.200.000,- per tahun dengan rata-rata $\mathrm{Rp}$ 940.000 ,- setiap pemanen per tahunnya. Jumlah produksi madu lebah hutan per musim panen dapat memberikan tambahan penghasilan alternatif bagi para pemanen.

\section{KESIMPULAN DAN SARAN}

Berdasarkan uraian tersebut di atas dapat disimpulkan beberapa hal yaitu :

1. Teknik pemanenan madu lebah hutan diawali dengan pengusiran lebah melalui pengasapan, pemanjatan pohon inang, penyortiran sarang lebah, dan penurunan sarang dengan menggunakan keranjang rotan atau kondre, dan pengemasan hasil berupa madu.

2. Jumlah produksi madu sebesar $1.601,25 \mathrm{~kg}$ per tahun. Pemanenan madu ini dapat memberikan penghasilan tambahan bagi masyarakat pemanen dengan pendapatan per tahun sebesar Rp 28.200.000,- dengan ratarata $\mathrm{Rp} 940.000,00$ setiap pemanennya.

Upaya pemanenan hasil hutan bukan kayu berupa madu perlu dilakukan kajian lanjutan tentang penerapan teknologi tepat guna yang lebih praktis dan menghasilkan madu yang lebih banyak dengan kualitas tinggi. Produksi, pembagian hasil dan berbagai proses serta teknik pemanenan madu di dalam hutan perlu didukung oleh aturan yang dikeluarkan oleh pemerintah desa beserta masyarakat khususnya para pemanen madu sehingga proses pemanenan tetap mampu menjaga kelestarian hutan dan hubungan kekerabatan para pemanen madu.

\section{DAF TAR BACAAN}

Departemen Tenaga Kerja Sulsel dan Lembaga Penelitian Unhas. 1995. Teknik Perburuan dan Pemungutan Madu Rimba. Lembaga Penelitian Unhas, Ujung Pandang.

Forest Watch Indonesia dan Global Forest Watch. 2001. Potret Keadaan Hutan Indonesia. Bogor, Indonesia: Forest Watch Indonesia dan Washington D.C.: Global Forest Watch

Nindrayati. 2000. Telaahan Implementasi Kebijakan HKm Berdasarkan Potensi Lokal di Kabupaten Takalar Sulawesi Selatan (Studi Kasus di Desa Komara). Tesis Program Pasca Sarjana Program Studi IImu Kehutanan, Universitas Mulawarman. Samarinda (Tidak Dipublikasikan).

Pusat Perlebahan Apiari Pramuka. 2003. Lebah Madu: Cara Beternak dan Pemanfaatan. Penebar Swadaya. Jakarta.

Sarwono, B. 2001. Kiat Mengatasi Permasalahan Praktis Lebah Madu. Agromedia Pustaka. Jakarta.

Sihombing, D.T.H. 1997. IImu Ternak Lebah Madu. Gajah Mada University Press. Jogjakarta. 
Sila, A.M. 1997. Madu Tropis Gizi dan Kesehatan Masyarakat. Lembaga Penelitian Unhas. Makassar.

Sumoprastowo, R.M. dan R.A. Suprapto. 1993. Beternak Lebah Madu Modern. PT. Bhatara Niaga Media. Jakarta.

Suyanto, Y. dan S. Sastroprawiro. 1996. Pembudidayaan Lebah Madu Dalam Rangka Peningkatan Kesejahteraan Masyarakat Desa
Sekitar Hutan di Pulau Jawa. Duta Rimba/Maret - April/ 20 (189 - 190 ). Jakarta.

Soeradjotanojo, S. dan Kardjono. 1992. Membina Usaha Industri Ternak Lebah Madu Apis mellifera. Balai Pustaka. Jakarta.

Widjaja, M.C. 1993. Teknik Pemanenan Lebah Hutan (Apis dorsata F.) Tanpa Merusak Populasi Koloni Lebah Madu. Duta Rimba/Maret - April/ 19 ( 153 - 154) : 22 24. Jakarta.

Diterima : 22 Desember 2007

\section{A. Mujetahid M.}

Lab. Pemanenan Hasil Hutan

Fakultas Kehutanan Universitas Hasanuddin

Jl. Perintis Kemerdekaan Km. 10 Tamalanrea, Makassar 90245

TIp./Fax. : (0411) 589592 